\title{
Effect of long-term selenium yeast intervention on activity and gene expression of antioxidant and xenobiotic metabolising enzymes in healthy elderly volunteers from the Danish Prevention of Cancer by Intervention by Selenium (PRECISE) Pilot Study
}

\author{
Gitte Ravn-Haren ${ }^{1}$, Britta N. Krath ${ }^{1}$, Kim Overvad $^{2}$, Søren Cold ${ }^{3}$, Sven Moesgaard ${ }^{4}$, Erik H. Larsen ${ }^{5}$ \\ and Lars O. Dragsted ${ }^{1}$ \\ ${ }^{1}$ Department of Toxicology and Risk Assessment, National Food Institute, Technical University of Denmark, Mфrkhфj Bygade 19, \\ Soborg 2860, Denmark \\ ${ }^{2}$ Department of Clinical Epidemiology, Aalborg Hospital, Aarhus University Hospital, Aalborg, Denmark \\ ${ }^{3}$ Department of Oncology, Odense University Hospital, Odense, Denmark \\ ${ }^{4}$ Pharma Nord, Vejle, Denmark \\ ${ }^{5}$ Department of Food Chemistry, National Food Institute, Technical University of Denmark, Søborg, Denmark
}

(Received 5 December 2006 - Revised 16 October 2007 - Accepted 16 October 2007 - First published online 6 December 2007)

Numerous mechanisms have been proposed to explain the anti-carcinogenic effects of Se, among them altered carcinogen metabolism. We investigated the effect of Se supplementation on activities of glutathione peroxidase (GPX), glutathione reductase (GR) and glutathione $S$-transferase (GST) in different blood compartments, and expression of selected phase 1 and phase 2 genes in leucocytes (GPX1, $\gamma$-glutamylcysteine ligase catalytic subunit (GCLC), AP-1 transcription factor Fos-related antigen 1 (Fral), NAD(P)H:quinone oxidoreductase (NQO1), and aryl hydrocarbon receptor repressor (AhRR)). Healthy elderly Danes ( $n$ 105; age 71.3 (SD 4.26) years; $36 \%$ reporting use of multivitamin/mineral supplements) participated and were supplemented daily for 5 years with placebo, $100 \mu \mathrm{g}, 200 \mu \mathrm{g}$ or $300 \mu \mathrm{g}$ Se as Se-enriched yeast $\left(\right.$ SelenoPrecise ${ }^{\circledR}$ ). Blood samples were collected after 5 years of intervention. When all four groups were compared we found no effect of Se supplementation on plasma GPX or GR, on erythrocyte GPX, GR or GST, or on thrombocyte GR or GST. We found increased thrombocyte GPX activity at the two highest dosage levels in women only, but not in men. No effects on GPX1, NQO1 or AhRR gene expression were found. When all Se-supplemented groups were pooled we found significant down regulation of the expression of some phase 2 genes (GCLC, Fral). A significant increase in $A h R R$ gene expression with smoking was found but was independent of Se supplementation. Down regulation of phase 2 genes could increase the risk of cancer. However, further studies are needed to establish whether the observed effect in leucocytes reflects a similar expression pattern in target tissues.

Human nutrition: Selenium: Oxidative defence: Electrophile response elements

Se is an essential micronutrient that is incorporated specifically as selenocysteine into the active site of selenoproteins (such as the glutathione peroxidases; GPX). Se as an antioxidant helps to maintain intracellular redox balance, promoting a reducing environment and thereby limiting oxidative damage caused by free radicals. It has been suggested that Se intakes above the level necessary to saturate selenoproteins can reduce the risk of cancer. In the Nutritional Prevention of Cancer Trial published in 1996, a daily supplement of $200 \mu \mathrm{g} \mathrm{Se}$, as Se-enriched yeast, in patients with a history of basal cell or squamous cell carcinoma of the skin showed a significant increase in recurrence of skin cancer, but a significant reduction in overall cancer risk, in risk of cancers with a more severe prognosis, such as prostate, colorectal and lung cancer, and consequently a decrease in total cancer mortality $^{(1-3)}$. The strongest effect was found in individuals with a baseline plasma Se (pSe) level below $106 \mu \mathrm{g} / \mathrm{l}$, while no protective effect was found in the upper tertile ${ }^{(4)}$. Most of the participants in the Nutritional Prevention of Cancer Trial had initial Se intakes above the level required to saturate selenoproteins, indicating that the observed effects of Se are not limited to antioxidant functions through selenoproteins. Based on results from numerous rodent cancer models, it has also been proposed that alterations in carcinogen metabolism

Abbreviations: AhRR, aryl hydrocarbon receptor repressor; EpRE, electrophile response element; Fra1, Fos-related antigen 1; GCLC, $\gamma$-glutamylcysteine ligase catalytic subunit; GPX, glutathione peroxidase; GR, glutathione reductase; GSH, glutathione; GST, glutathione S-transferase; NQO1, NAD(P)H:quinone oxidoreductase; pSe, plasma Se; tGPX, thrombocyte glutathione peroxidase; XRE, xenobiotic response element.

* Corresponding author: Dr Gitte Ravn-Haren, fax +45 72347699, email grh@food.dtu.dk 
resulting in increased enzymic defence play a role in the cancer-protective effect of Se. But results are far from consistent and may vary with choice of animal model, choice of carcinogen, Se source, Se dosage level and tissue studied ${ }^{(5-7)}$

Se deficiency has been associated with a decrease in GPX activity as well as in mRNA levels ${ }^{(8)}$. Besides affecting expression and activity of selenoproteins, Se is also involved in the regulation of other gene products. Se supplementation has been reported to increase blood glutathione (GSH) levels, indicating reduced oxidative stress $^{(9)}$. Glutathione reductase (GR) is the principal enzyme maintaining GSH in its reduced form. GSH is also a cofactor for GPX and is necessary for GSH conjugation by glutathione $S$-transferases (GST). $\gamma$-Glutamylcysteine ligase (GCL) composed of a catalytic (GCLC) and a modulatory (GCLM) subunit is the first step in the de novo synthesis of $\mathrm{GSH}^{(10,11)}$. Common for GCLC and GCLM and other genes encoding phase 2 detoxifying enzymes, including $\mathrm{NAD}(\mathrm{P}) \mathrm{H}$ :quinone oxidoreductase (NQO1) and GST, is the presence of electrophile response elements (EpRE) in the promoter regions (TGACNNNGC), which mediate the transcriptional up regulation in response to a variety of inducing agents ${ }^{(12)}$. The AP-1 transcription factor Fos-related antigen 1 (Fral) may contain an EpRE in its promoter region ${ }^{(13)}$ and is able to down regulate $N Q O 1$ and $G C L C$ gene expression ${ }^{(14,15)}$ through embedded AP-1 sites $(\text { TGACTCA })^{(16,17)}$. Se could induce or repress these gene responses through EpRE.

Up regulation of genes encoding phase 1 xenobiotic metabolising enzymes in the liver has been reported in Se-deficient mice ${ }^{(18)}$. Some xenobiotics interact with the aryl hydrocarbon receptor (AhR) and transactivate target genes such as cytochrome $\mathrm{P} 450$ through the xenobiotic response element (XRE). The aryl hydrocarbon receptor repressor (AhRR) regulates AhR function by a negative feed-back mechanism, thereby down regulating genes that are regulated by $\mathrm{AhR}^{(19)}$. The promoter region of $A h R R$ contains 3 XRE binding sites, and could potentially be affected by Se supplementation ${ }^{(20)}$.

In Denmark, the average daily dietary Se intake (excluding supplements) is low compared with other countries ${ }^{(21)}$, being $42 \mu \mathrm{g} / \mathrm{d}$ for men and $33 \mu \mathrm{g} / \mathrm{d}$ for women according to the latest survey ${ }^{(22)}$. But Se supplementation through multivitamin and mineral supplements is very common, adding on average $25 \mu \mathrm{g}$. We assumed that a population like the Danish, with relatively low $\mathrm{Se}$ intakes, would be appropriate for studying the biological effects of Se supplementation.

The aim of the present study was to investigate whether the dietary Se intake of elderly Danes is sufficient to obtain saturation of GPX expression in different blood compartments, and whether increased Se intake will affect gene expression and activity of selected phase 2 enzymes and transcription factors containing EpRE or XRE in their promoter, as has been reported in animal studies. We therefore investigated whether a daily Se supplement of 100,200 or $300 \mu \mathrm{g}$ as Se-enriched yeast for 5 years would increase activities of GPX, GR and GST in erythrocytes, plasma or thrombocytes, and modulate gene expression of Fral, GCLC, GPX1, AhRR and NQO1 in leucocytes. The use of three dosage levels enabled us to look closer at dose-response relationships. We also investigated the overall effect of Se supplementation by pooling the supplemented groups and testing them against the placebo group.

\section{Materials and methods}

\section{Subjects and study design}

In 1999, a cohort of 500 men and women was established in Denmark. Participants were recruited from the county of Funen, were between the ages of 60 and 74 years, had no previous cancer diagnosed, had no severe or life-threatening diseases and a daily intake of Se supplementation not exceeding $50 \mu \mathrm{g}$ (a typical multivitamin/mineral supplement sold in Denmark contains $40-50 \mu \mathrm{g}$ inorganic Se). A 1-month run-in period where subjects were supplemented with placebo tablets ensured exclusion of participants who were not compliant. The study was a randomised, double-blinded, placebo-controlled intervention experiment with a parallel design. At recruitment each participant was randomised to one of four groups, a placebo group and three dosage levels: 100,200 or $300 \mu \mathrm{g}$ Se as Se-enriched yeast (SelenoPrecise ${ }^{\circledR}$; Pharma Nord, Vejle, Denmark). The Se-enriched yeast has previously been reported to consist of about $81 \%$ selenomethionine in the fraction liberated by proteolysis ${ }^{(23)}$. At study entry and at $6,12,18,24$, 36 and 60 months the participants visited the centre to donate a blood sample, collect tablets for the following period and answering questions concerning compliance and side effects, such as garlic breath, hair loss and nail brittleness. Based on counting of returned pill packets after years 1, 2 and 3 , compliance was $>96 \%$. No serious adverse effects were reported and there was no correlation to $\mathrm{Se}$ dose (details will be published elsewhere). The supplementation lasted 5 years. The last blood samples were collected after 5 years of supplementation and the present study was performed on a random sub-sample of 105 participants, selected consecutively among those who attended the centre for the terminal visit within a certain time period. All participants gave oral and written consent according to the second Helsinki declaration. The study was approved by the regional ethical committees of Vejle and Funen (journal no. 19980186).

\section{Blood sampling and storage}

After supine rest for $10 \mathrm{~min}$, blood samples were collected from non-fasting participants in $10 \mathrm{ml}$ EDTA-coated tubes (Becton Dickinson, Franklin Lakes, NJ, USA), and centrifuged for $15 \mathrm{~min}$ ( $150 \mathrm{~g}$; room temperature). Thrombocytes were isolated from the thrombocyte-rich plasma by centrifugation $(1500 \mathrm{~g}$; room temperature; $5 \mathrm{~min})$. The thrombocyte pellet was washed twice in $0.9 \% \mathrm{NaCl}$ and re-suspended in $0.5 \mathrm{ml} 0.9 \% \mathrm{NaCl}$. Erythrocytes and buffy coat were isolated by centrifugation $(1500 \mathrm{~g}$; room temperature; $10 \mathrm{~min})$. The buffy coat was re-suspended in RLT buffer (QIAgen, Ballerup, Denmark). Erythrocytes were lysed by adding an equal amount of MilliQ water to the tube. Plasma, thrombocytes, buffy coat and erythrocytes were stored at $-80^{\circ} \mathrm{C}$.

\section{Plasma selenium status}

pSe concentration was determined as previously described using an ELAN 6100 ICP-DRC-MS (PerkinElmer SCIEX, Concord, ON, Canada) equipped with an AS-91 autosampler (PerkinElmer, Norwalk, CT, USA) ${ }^{(24)}$. For every fifteen unknown plasma samples one duplicate sample, one field blank, one certified reference sample and three Se $(10 \mu \mathrm{g} / \mathrm{l})$ 
standard solutions were included. The latter were used to correct for instrumental drift. Based on the determination of field blanks the limit of detection was estimated at $0 \cdot 1 \mu \mathrm{g} \mathrm{Se} / \mathrm{l}$ and the uncertainty was estimated from the differences between double determinations at $2.1 \%$ relative SD. The accuracy was determined by including a reference sample with a known content of 73 (SD 8) $\mu \mathrm{g} / \mathrm{l}$ (Seronorm Serum; Nycomed Pharma Diagnostics, Oslo, Norway). We found an Se concentration of 77 (SD 6) $\mu \mathrm{g} / \mathrm{l}$ in this sample.

Defence enzyme activities (glutathione peroxidase, glutathione reductase and glutathione S-transferase)

Erythrocyte, plasma and thrombocyte GPX and GR activities were determined spectrophotometrically on a Cobas Mira analyser (F. Hoffmann-La Roche Ltd, Basel, Switzerland) according to Wheeler et al. ${ }^{(25)}$. $t$-Butyl hydroperoxide was used as substrate for GPX. GST activity was measured in thrombocytes and erythrocytes as previously described ${ }^{(26)}$. Enzyme activities measured in erythrocyte lysates were related to the amount of $\mathrm{Hb}$ in the sample. Enzyme activities determined in thrombocytes and plasma were related to the amount of total protein. $\mathrm{Hb}$ and total protein contents were determined using commercially available kits (catalogue no. HG 980, Randox, Crumlin, Co. Antrim, UK; catalogue no. A11A01669, ABX Diagnostics, Montpellier, France, respectively). Control samples (erythrocytes, plasma and thrombocytes) were included for every tenth sample analysed. Inter- and intraday variations for the control samples were $<7 \%$.

\section{RNA isolation and cDNA synthesis}

Total RNA was extracted from the buffy coat using the QIAamp ${ }^{\circledR}$ RNA blood mini kit (QIAgen, Ballerup, Denmark). The concentration and purity of the RNA was determined by measuring the absorbance at 260 and $280 \mathrm{~nm}$ using the NanoDrop ${ }^{\circledR}$ ND-1000 UV-Vis spectrophotometer (NanoDrop Technologies, Wilmington, DE, USA). A ratio $\left(\mathrm{A}_{260}: \mathrm{A}_{280}\right)$ of $>1.8$ indicated suitable purity. First-strand cDNA was synthesised using $500 \mathrm{ng}$ total RNA in a final volume of $10 \mu \mathrm{l}$ with Random Hexamer primer and Superscript ${ }^{\mathrm{TM}}$ II Rnase H-RT according to the manufacturers (Invitrogen, Taastrup, Denmark).

\section{Primer and probe design}

Oligonucleotide primers and TaqMan $^{\circledR}$ probes were designed with Primer Express software v. 1.5 (Applied Biosystems, Stockholm, Sweden), based on sequences from the Genbank database (Table 1). Genomic DNA amplification was excluded whenever possible by designing intron spanning probes.

Leucocyte mRNA quantification of Fos-related antigen 1, glutathione peroxidase 1, $\gamma$-glutamylcysteine ligase catalytic subunit, $\mathrm{NAD}(\mathrm{P}) \mathrm{H}$ :quinone oxidoreductase and aryl hydrocarbon receptor repressor. Real-time PCR of the five genes was performed on an ABI PRISM ${ }^{\circledR}$ 7900HT Sequence Detection System (Applied Biosystems, Stockholm, Sweden). The PCR reaction was determined in a $20 \mu \mathrm{l}$ final volume adding 2 ng cDNA, using TaqMan ${ }^{\circledR}$ Universal PCR Master Mix (Applied Biosystems, Stockholm, Sweden). For each target gene, the probe concentration was $0.3 \mu \mathrm{M}$ and the primer concentrations for the detection of GCLC, AhRR and NQO1 genes were $0.3 \mu \mathrm{M}, 0.5 \mu \mathrm{M}$ for GPXI, and $0.9 \mu \mathrm{M}$ for Fral. The constitutively expressed 18S rRNA primer/probe-set (Applied Biosystems, Stockholm, Sweden) was selected as an endogenous control to correct for potential variation in RNA loading or efficiency of the amplification reaction and used as recommended by the manufacturers.

The PCR amplification was performed in ninety-six-well plates in triplicates using the following cycling protocol: $50^{\circ} \mathrm{C}$ for $2 \mathrm{~min}, 95^{\circ} \mathrm{C}$ for $10 \mathrm{~min}$, forty-five cycles at $95^{\circ} \mathrm{C}$ for $15 \mathrm{~s}$ and $60^{\circ} \mathrm{C}$ for $1 \mathrm{~min}$. To confirm equal amplification efficiencies, we used the criterion of a regression slope of less than $0 \cdot 1$ for each target gene normalised to $18 \mathrm{~S}$ rRNA. This confirms that we could use the comparative cycle threshold $(\mathrm{Ct})$ method for the relative quantification of target without running standard curves on the same plate (data not shown). Relative changes in gene expression were calculated

Table 1. Oligonucleotides and $\operatorname{TaqMan}^{\circledR}$ fluorogenic probes

\begin{tabular}{|c|c|c|c|}
\hline Gene & Genbank & Primer/probe & Sequence $5^{\prime}-3^{\prime}$ \\
\hline \multirow[t]{3}{*}{ GPX1 } & AY327818 & Sense & CCCGTGCAACCAGTTTGG \\
\hline & & Antisense & TGAGGGAATTCAGAATCTCTTCGT \\
\hline & & TaqMan ${ }^{\circledR}$ probe & 6-FAM-CATCAGGAGAACGCC-MGB \\
\hline \multirow[t]{3}{*}{ GCLC } & NM_001498 & Sense & CGGCACAAGGACGTTCTCA \\
\hline & & Antisense & ACCGGACTTTTTTTATTTTCATGATCA \\
\hline & & TaqMan ${ }^{\circledR}$ probe & 6-FAM-CGATGAGGTGGAATAC-MGB \\
\hline \multirow[t]{3}{*}{ NQO1 } & NM_000903 & Sense & СTTCAATCCCATCATTTCCAGAA \\
\hline & & Antisense & GACTCGGCAGGATACTGAAAGTTC \\
\hline & & TaqMan ${ }^{\circledR}$ probe & 6-FAM-CATCACAGGTAAACTGAAG-MGB \\
\hline \multirow[t]{3}{*}{ Fra1 } & NM_005438 & Sense & GCCGCCCTGTACCTTGTATC \\
\hline & & Antisense & CAGTGCCTCAGGTTCAAGCA \\
\hline & & TaqMan ${ }^{\circledR}$ probe & 6-FAM-CTTTCCCCAGGGCCT-MGB \\
\hline \multirow[t]{3}{*}{ AhRR } & NM_020731 & Sense & GAATCGGAACTGCATGGAAAA \\
\hline & & Antisense & CCAAAACGCCGCTCTCTCT \\
\hline & & TaqMan ${ }^{\circledR}$ probe & 6-FAM-CAATTACTCAGCAGGAAGG-MGB \\
\hline
\end{tabular}

GPX1, glutathione peroxidase 1; 6-FAM, 6-carboxyfluorescein; MGB, minor groove binding; GCLC, $\gamma$-glutamylcysteine ligase catalytic subunit; NQO1, NAD(P)H quinone oxidoreductase 1; Fra1, FOS-like antigen 1; AhRR, aryl-hydrocarbon receptor repressor. 
by the $\Delta \Delta \mathrm{Ct}$ method (Applied Biosystems, 2001, User Bulletin no. 2, ABI PRISM 7700 Sequence Detection System, Foster City, CA, USA). Inter-plate variation for a control sample ( $n$ 27) was $<2 \%$ for all genes.

\section{Statistical analysis}

Treatment effects were analysed with the general linear model, with sex, smoking and their interactions with treatment included in the model. Weight was significantly higher among men than women, and was therefore included in the model as a covariate. Since a large proportion of subjects reported taking multivitamin/mineral supplements, use of additional supplements was included in the statistical analyses as a covariate. For comparison of two groups, $t$ tests were used (placebo against pooled Se-supplemented groups). Data that could not meet the criteria of variance homogeneity and normal distribution after $\log$ transformation were analysed by non-parametric tests (Kruskal-Wallis $\mathrm{H}$ test or MannWhitney $U$ test). Group differences for categorical data were analysed using the $\chi^{2}$ test. For all tests a $P$ value less than 0.05 was considered statistically significant. Pearson correlations were used to identify correlating variables. All statistical analyses were performed using SAS (SAS Institute, Cary, NC, USA).

\section{Results}

\section{Study population}

Baseline characteristics for the study participants are presented in Table 2 as mean values and standard deviations (age, weight) or as percentages (smoking status, sex). The participants were predominantly non-smokers and in the selected sub-sample for the present study women assigned to the highest dosage level were older compared with women in the lowest and medium dosage groups (Table 2). Women had significantly lower body weight compared with men $(P<0 \cdot 001)$. Otherwise, there were no statistically significant differences in baseline characteristics between the groups.

Records of the use of multivitamin/mineral supplements among the participants (registered at time of final blood sampling, year 5) indicate that on average $36 \%$ took additional supplements (as ordinary multivitamin/mineral tablets); however, the percentage of supplement users was about twice as high among participants from the highest dosage group compared with the rest (Table 2). No participants reported use of specific Se supplements.

\section{Compliance}

pSe concentration was measured to test for compliance. Se status increased linearly $\left(R^{2} 0.98 ; P<0.0001\right)$ with increasing Se intake (Table 3), indicating a high degree of compliance. Smoking status did not influence pSe $(P>0.05)$ (data not shown).

\section{Enzyme activities}

There was a statistically significant effect on thrombocyte GPX activity (tGPX) $(P=0 \cdot 003)$, with a statistically significant treatment $\times$ sex interaction $(P=0.008)$. When subjects were stratified according to sex, we found an effect of Se supplementation on tGPX activity in women only $\left(P_{\text {women }}=0.006\right)$ (Table 3 ). tGPX activity was significantly increased in groups supplemented with 200 or $300 \mu \mathrm{g} / \mathrm{d}\left(P_{\text {placebo }-200 \mu \mathrm{g}}=0.001\right.$; $\left.P_{\text {placebo }-300 \mu \mathrm{g}}=0.008\right)$, while there was a tendency towards increased tGPX activity at the lowest dosage level $\left(P_{\text {placebo-100 }}\right.$ $\mu \mathrm{g}=0.084)$ compared with placebo. We found no statistically significant difference in tGPX between the two highest dosage levels $\left(P_{200 \mu \mathrm{g}-300 \mu \mathrm{g}}=0 \cdot 688\right)$. No effect of Se supplementation on tGPX was observed in men $\left(P_{\text {men }}=0.401\right)$. We found no effect of Se supplementation on plasma GR or GPX, on erythrocyte GR, GPX or GST, or on GR or GST measured in thrombocytes (Table 3 ). We found no interaction with smoking on any of the activities.

When all supplemented groups were pooled and tested against the placebo group, only tGPX was significantly increased with $\mathrm{Se}$ supplementation $(P=0.027)$ and, again, only women responded $\left(P_{\text {women }}=0.004 ; P_{\text {men }}=0.596\right)$. pSe correlated with plasma GPX activity $(P=0.046 ; r 0.212)$ but not tGPX $(P=0 \cdot 106)$ or erythrocyte GPX $(P=0 \cdot 162)$.

\section{Gene expression}

Se supplementation did not affect gene expression of $G P X 1$, Fral, GCLC, NQO1 or AhRR in leucocytes (Table 4), when all groups were tested against each other. There was a large

Table 2. Baseline characteristics of the study participants (Mean values and standard deviations or percentages)

\begin{tabular}{|c|c|c|c|c|c|c|c|c|c|c|c|c|}
\hline & \multicolumn{3}{|c|}{ Placebo } & \multicolumn{3}{|c|}{$100 \mu \mathrm{g} / \mathrm{d}$} & \multicolumn{3}{|c|}{$200 \mu \mathrm{g} / \mathrm{d}$} & \multicolumn{3}{|c|}{$300 \mu \mathrm{g} / \mathrm{d}$} \\
\hline & $n$ & Mean & SD & $n$ & Mean & SD & $n$ & Mean & SD & $n$ & Mean & SD \\
\hline $\begin{array}{l}\text { Age (years) } \\
\text { Weight }(\mathrm{kg})\end{array}$ & 28 & $70 \cdot 4$ & $3 \cdot 8$ & 27 & $70 \cdot 3$ & 3.6 & 23 & $71 \cdot 6$ & $4 \cdot 2$ & 27 & $73 \cdot 0$ & $5 \cdot 0$ \\
\hline All subjects & 28 & 78.5 & 12 & 27 & 73.1 & 12 & 23 & $75 \cdot 6$ & 15 & 27 & 80.6 & 13 \\
\hline Men & 13 & 83.3 & $8 \cdot 2$ & 12 & 80.9 & $9 \cdot 1$ & 9 & $87 \cdot 7$ & 10 & 15 & $81 \cdot 7$ & 11 \\
\hline Women* & 15 & $74 \cdot 3$ & 13 & 15 & $67 \cdot 0$ & $9 \cdot 4$ & 14 & $67 \cdot 7$ & 12 & 12 & $79.2 \dagger$ & 14 \\
\hline Smokers (\%) & 28 & \multicolumn{2}{|c|}{36} & 27 & \multicolumn{2}{|c|}{22} & 23 & \multicolumn{2}{|c|}{22} & 27 & \multicolumn{2}{|c|}{19} \\
\hline Supplement users (\%) & 28 & \multicolumn{2}{|c|}{29} & 27 & \multicolumn{2}{|c|}{26} & 23 & \multicolumn{2}{|c|}{35} & 27 & \multicolumn{2}{|c|}{56} \\
\hline Males (\%) & 28 & \multicolumn{2}{|c|}{46} & 27 & \multicolumn{2}{|c|}{44} & 23 & \multicolumn{2}{|c|}{39} & 27 & \multicolumn{2}{|c|}{56} \\
\hline
\end{tabular}

${ }^{*}$ Compared with men, women had significantly lower body weight $(P<0.001$; ANOVA).

† Highest dosage group was significantly different from lowest dosage group $(100 \mu \mathrm{g} / \mathrm{d})$ and medium dosage group $(200 \mu \mathrm{g} / \mathrm{d})(P<0.05 ;$ ANOVA) 
Table 3. Effect of selenium supplementation on plasma selenium and activities of glutathione peroxidase (GPX), glutathione reductase (GR) and glutathione $S$-transferase (GST) measured in plasma, erythrocytes or thrombocytes

(Medians and 10th and 90th percentiles and means and standard deviations)

\begin{tabular}{|c|c|c|c|c|c|c|}
\hline & & & Placebo & $100 \mu \mathrm{g} / \mathrm{d}$ & $200 \mu \mathrm{g} / \mathrm{d}$ & $300 \mu \mathrm{g} / \mathrm{d}$ \\
\hline \multicolumn{7}{|l|}{ Plasma } \\
\hline \multirow{5}{*}{$\operatorname{Se}(\mu g / l)$} & All & $n$ & 24 & 22 & 20 & 23 \\
\hline & & Median & $93 \cdot 0$ & $159^{*}$ & $207^{\star}$ & $242^{\star}$ \\
\hline & & 10th, 90th percentiles & $77 \cdot 3,105$ & 134,217 & 177,266 & 203,341 \\
\hline & & Mean & 92 & $165^{*}$ & $221^{*}$ & $260^{*}$ \\
\hline & & SD & $11 \cdot 2$ & $31 \cdot 6$ & $42 \cdot 3$ & $59 \cdot 7$ \\
\hline \multirow[t]{5}{*}{ GPX (units per g protein) } & All & $n$ & 28 & 27 & 23 & 27 \\
\hline & & Median & 14.0 & $15 \cdot 0$ & $14 \cdot 2$ & 14.4 \\
\hline & & 10th, 90th percentiles & $11 \cdot 0,15 \cdot 9$ & $12 \cdot 4,17 \cdot 2$ & $12 \cdot 0,17 \cdot 4$ & $12 \cdot 6,16 \cdot 9$ \\
\hline & & Mean & 13.7 & $14 \cdot 7$ & 14.5 & 14.5 \\
\hline & & SD & 1.95 & 2.35 & 2.31 & $2 \cdot 10$ \\
\hline \multirow{5}{*}{ GR (units per g protein) } & All & $n$ & 28 & 27 & 23 & 27 \\
\hline & & Median & 0.85 & 0.85 & 0.88 & 0.85 \\
\hline & & 10th, 90th percentiles & $0.72,1.12$ & $0.71,1.01$ & $0.65,1.06$ & $0.74,0.99$ \\
\hline & & Mean & 0.91 & 0.85 & 0.87 & 0.87 \\
\hline & & SD & 0.26 & $0 \cdot 12$ & $0 \cdot 17$ & 0.13 \\
\hline \multicolumn{7}{|l|}{ Erythrocytes (units per g Hb) } \\
\hline \multirow[t]{5}{*}{ GPX } & All & $n$ & 28 & 27 & 23 & 27 \\
\hline & & Median & $92 \cdot 8$ & 99.5 & 96.5 & 99.4 \\
\hline & & 10th, 90th percentiles & $69 \cdot 3,110$ & $66 \cdot 0,131$ & $78 \cdot 2,135$ & $75 \cdot 0,124$ \\
\hline & & Mean & $92 \cdot 7$ & $98 \cdot 8$ & 104 & $98 \cdot 8$ \\
\hline & & SD & $18 \cdot 0$ & 24.9 & $28 \cdot 1$ & $19 \cdot 0$ \\
\hline \multirow[t]{5}{*}{ GR } & All & $n$ & 28 & 27 & 23 & 27 \\
\hline & & Median & 11.5 & $11 \cdot 7$ & 11.5 & 12.4 \\
\hline & & 10th, 90th percentiles & $9 \cdot 49,13.4$ & $9 \cdot 60,13 \cdot 0$ & $10 \cdot 1,12 \cdot 9$ & $10 \cdot 2,14 \cdot 1$ \\
\hline & & Mean & 11.4 & 11.5 & 11.4 & $12 \cdot 3$ \\
\hline & & SD & 1.6 & 1.5 & $1 \cdot 1$ & 1.5 \\
\hline \multirow[t]{5}{*}{ GST } & All & $n$ & 28 & 27 & 23 & 27 \\
\hline & & Median & 8.25 & 7.72 & 8.05 & 8.40 \\
\hline & & 10th, 90th percentiles & $5 \cdot 20,12 \cdot 1$ & $5 \cdot 55,10 \cdot 7$ & $4 \cdot 15,10 \cdot 7$ & $6 \cdot 08,12 \cdot 0$ \\
\hline & & Mean & 8.42 & 8.00 & 7.66 & 8.86 \\
\hline & & SD & $2 \cdot 9$ & $2 \cdot 2$ & $2 \cdot 9$ & $3 \cdot 2$ \\
\hline \multicolumn{7}{|c|}{ Thrombocytes (units per g protein) } \\
\hline \multirow[t]{15}{*}{ GPX } & All & $n$ & 28 & 27 & 23 & 25 \\
\hline & & Median & 202 & 224 & 300 & 315 \\
\hline & & 10th, 90th percentiles & $80 \cdot 3,393$ & 129,431 & $84 \cdot 8,590$ & 125,543 \\
\hline & & Mean & 221 & 251 & 323 & 320 \\
\hline & & SD & 146 & 113 & 217 & 174 \\
\hline & Men & $n$ & 13 & 12 & 9 & 14 \\
\hline & & Median & 224 & 196 & 138 & 208 \\
\hline & & 10th, 90th percentiles & $75 \cdot 8,371$ & 130,343 & $66 \cdot 3,473$ & $86 \cdot 8,515$ \\
\hline & & Mean & 218 & 224 & 222 & 283 \\
\hline & & SD & 126 & $96 \cdot 1$ & 194 & 183 \\
\hline & Women & $n$ & 15 & 15 & 14 & 11 \\
\hline & & Median & 155 & 251 & $312^{*}$ & $336^{\star}$ \\
\hline & & 10th, 90th percentiles & $90 \cdot 8,427$ & 130,441 & 214,670 & 187,553 \\
\hline & & Mean & 225 & 274 & $389^{*}$ & $368^{\star}$ \\
\hline & & SD & 165 & 124 & 212 & 157 \\
\hline \multirow[t]{5}{*}{ GR } & All & $n$ & 27 & 27 & 22 & 25 \\
\hline & & Median & $47 \cdot 9$ & 41.6 & $49 \cdot 0$ & 44.9 \\
\hline & & 10th, 90th percentiles & $28 \cdot 8,65 \cdot 9$ & $20 \cdot 9,54.5$ & $20 \cdot 1,59 \cdot 9$ & $21 \cdot 5,70 \cdot 6$ \\
\hline & & Mean & $47 \cdot 6$ & $40 \cdot 1$ & $44 \cdot 1$ & $45 \cdot 8$ \\
\hline & & SD & $16 \cdot 4$ & $15 \cdot 0$ & $14 \cdot 8$ & $17 \cdot 7$ \\
\hline \multirow[t]{5}{*}{ GST } & All & $n$ & 27 & 27 & 22 & 25 \\
\hline & & Median & 110 & 69.5 & 107 & 73.8 \\
\hline & & 10th, 90th percentiles & $42 \cdot 8,191$ & $33 \cdot 1,168$ & $32 \cdot 9,233$ & $33 \cdot 9,164$ \\
\hline & & Mean & 110 & 95.4 & 128 & 92.2 \\
\hline & & SD & $57 \cdot 2$ & $58 \cdot 3$ & 104 & 59.5 \\
\hline
\end{tabular}

*Significantly different from placebo group $(P<0.05 ;$ ANOVA).

inter-individual variation in the expression of the transcription factors Fral and AhRR, especially in the placebo group (Table 4).

When the Se-supplemented groups were pooled and tested against placebo, we found a statistically significant decrease in expression of Fral and GCLC $(P=0.019$ and $P=0.042$, respectively) and a tendency towards a decreased expression of NQO1 $(P=0.067)$ and $A h R R(P=0.085)$. There was no effect of Se on GPXI $(P=0 \cdot 281)$. AhRR was the only gene 
Table 4. Effect of selenium supplementation on glutathione peroxidase 1 (GPX1), y-glutamylcysteine ligase catalytic subunit $(G C L C), N A D(P) H$ quinone oxidoreductase 1 (NQO1), FOS-like antigen 1 (Fra1) and aryl-hydrocarbon receptor repressor (AhRR) gene expression normalised to 18S rRNA

(Medians and 10th and 90th percentiles and means and standard deviations)

\begin{tabular}{|c|c|c|c|c|c|}
\hline & & Placebo & $100 \mu \mathrm{g} / \mathrm{d}$ & $200 \mu \mathrm{g} / \mathrm{d}$ & $300 \mu \mathrm{g} / \mathrm{d}$ \\
\hline \multirow[t]{5}{*}{ GPX1 } & $n$ & 27 & 26 & 23 & 26 \\
\hline & Median & 0.90 & 0.88 & 0.82 & 0.86 \\
\hline & 10th, 90th percentiles & $0.55,1.54$ & $0.55,1.30$ & $0.71,1.34$ & $0.59,1.41$ \\
\hline & Mean & 1.05 & 0.91 & 0.95 & 0.91 \\
\hline & SD & 0.58 & 0.31 & 0.33 & 0.34 \\
\hline \multirow[t]{5}{*}{ GCLC } & $n$ & 27 & 26 & 23 & 26 \\
\hline & Median & 0.98 & 0.75 & 0.86 & 0.75 \\
\hline & 10th, 90th percentiles & $0.62,1.59$ & $0.47,1.08$ & $0.49,1.37$ & $0.57,1.42$ \\
\hline & Mean & 1.02 & 0.81 & 0.88 & 0.93 \\
\hline & SD & 0.39 & 0.3 & 0.38 & 0.55 \\
\hline \multirow[t]{5}{*}{ NQO1 } & $n$ & 27 & 26 & 23 & 26 \\
\hline & Median & 0.98 & 0.74 & 0.81 & 0.84 \\
\hline & 10th, 90th percentiles & $0.52,1.59$ & $0.50,1.13$ & $0.56,1.10$ & $0.49,1.33$ \\
\hline & Mean & 1.05 & 0.82 & 0.86 & 0.91 \\
\hline & SD & 0.54 & 0.42 & 0.34 & 0.41 \\
\hline \multirow[t]{5}{*}{ Fra1 } & $n$ & 27 & 26 & 23 & 26 \\
\hline & Median & 1.08 & 0.66 & 0.44 & 0.53 \\
\hline & 10th, 90th percentiles & $0.25,2.85$ & $0.11,1.77$ & $0.13,1.34$ & $0 \cdot 12,2 \cdot 18$ \\
\hline & Mean & 1.8 & 0.94 & 0.83 & 1.0 \\
\hline & SD & 3.0 & $1 \cdot 14$ & $1 \cdot 19$ & $1 \cdot 36$ \\
\hline \multirow[t]{5}{*}{$A h R R$} & $n$ & 27 & 26 & 23 & 26 \\
\hline & Median & 0.69 & 0.71 & 0.65 & 0.78 \\
\hline & 10th, 90th percentiles & $0.38,4.36$ & $0.27,1.86$ & $0.21,1.58$ & $0.22,1.96$ \\
\hline & Mean & 1.82 & 1.0 & 1.07 & $1 \cdot 22$ \\
\hline & SD & 2.39 & 0.93 & 1.56 & 2.05 \\
\hline
\end{tabular}

expression marker influenced by smoking status. Smoking increased the expression of $A h R R(P=0 \cdot 0001)$ (Fig. 1), an effect that was independent of Se supplementation.

\section{Discussion}

The anti-carcinogenic effects of Se have been linked to increased expression of protective enzymes. In the present study, we investigated the effect of 5 years of Se supplementation on the activity and gene expression of selected

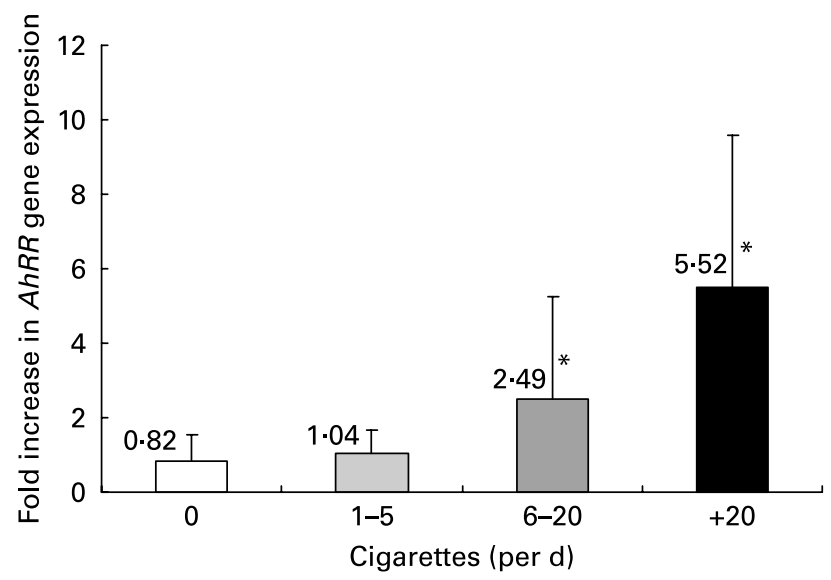

Fig. 1. Effect of smoking on gene expression of aryl hydrocarbon receptor repressor $(A h R R)$ relative to the mean expression in the placebo group. Values are means, with standard deviations represented by vertical bars. Participants are sub-divided according to number of cigarettes smoked per $\mathrm{d}$ 0 ( $n$ 77); 1-5 ( $n$ 8); 6-19 ( $n 11) ;+20(n 6)$. Pipe and cigar smokers are placed in the group with smokers of $1-5$ cigarettes per $d$. * Mean value is significantly different from that of non-smokers $(P<0.05$; Kruskal-Wallis). selenoproteins and genes involved in carcinogen metabolism. The pSe concentration was determined to test for compliance and we found a statistically significant increase in pSe with increasing $\mathrm{Se}$ supplement intake. It has previously been shown in numerous studies that pGPX and eGPX activities increase with Se intake, and that the increase reaches a plateau at intakes corresponding to pSe concentrations of about $70-90 \mu \mathrm{g} / \mathrm{l}$ and higher ${ }^{(27,28)}$. In the present study pSe concentrations in the placebo group were between 71 and $111 \mu \mathrm{g} / \mathrm{l}$ with a mean of $92 \mu \mathrm{g} / \mathrm{l}$. If we assume that the pSe in the control group is representative of the mean Se status in the participants before entry into the study, the lack of effect on pGPX and eGPX activities could be explained by these high baseline values, indicating that GPX is saturated in erythrocytes and plasma. We found a statistically significant increase in tGPX activity with Se supplementation, using Se-enriched yeast which consists primarily of the organic Se compound selenomethionine $^{(23)}$. A sub-group analysis showed that the effect of Se was sex specific. Se supplementation only affected tGPX activity in women, and only at the two highest dosage levels. The responses at these two levels were not statistically different, suggesting that tGPX activity is saturated at pSe concentrations between 165 and $221 \mu \mathrm{g} / \mathrm{l}$ (means of the two groups). This is a bit higher than previously reported where tGPX activity plateaued at pSe concentrations $<150 \mu \mathrm{g} / \mathrm{l}^{(27-30)}$. tGPX activity has been reported to saturate at higher pSe concentrations compared with eGPX and pGPX $^{(31)}$, which could explain the observed positive effect on GPX activity in thrombocytes. We are not aware of other studies reporting this sex-specific difference in tGPX activity in response to Se supplementation, and we cannot exclude that a similar effect would have been observed in men, had 
the number of participants been higher. Although not statistically significant, we note that GPX activity in all blood fractions increased with Se supplementation. In the present study, five years of Se supplementation did not affect GR activity in plasma, erythrocytes or thrombocytes, or GST activity in erythrocytes or thrombocytes.

Large inter-individual differences in response to Se supplementation have previously been reported ${ }^{(32)}$. Brown et al. found that the lower the baseline activity, the greater was the increase in response to Se supplementation. Thus it is possible that we would have seen effects of Se supplementation on GPX activity in erythrocytes and plasma if we had had baseline measurements available, thereby allowing us to investigate the individual responses, at least in individuals having low baseline levels.

GPX activity was measured in three different blood compartments, and only pGPX correlated weakly with pSe concentration. Nève et al. have previously reported significant correlations between pSe and pGPX and tGPX activities ${ }^{(31)}$ but we were not able to show any correlations between pSe and eGPX or tGPX activity. We did not measure Se status in erythrocytes or thrombocytes and it is possible that $\mathrm{Se}$ is channelled differently into various blood compartments as GPX synthesis is requested.

Smoking has been reported to decrease Se status and GPX activity $^{(33,34)}$. We found no interactions with smoking. One possible explanation could be that the group of smokers in the present study was much smaller than the group of nonsmokers, and individual smokers were very different regarding smoking habits. Some participants smoked very rarely while others smoked every day.

It has been hypothesised that Se at pharmacological doses would influence expression of phase 1 and phase 2 genes containing XRE or EpRE in their promoters ${ }^{(7)}$. We found no dose-response relationship on expression of AhRR, GPXl, GCLC, NQOI or Fral in leucocytes. Pooling the Se groups and testing them against the placebo group showed decreased expression of Fral, GCLC and NQO1, although the latter did not reach statistical significance. Fral has been reported to down regulate $G C L C$ and $N Q O 1^{(14,15)}$. If this were the case in the present study, we would have expected to see an up regulation of Fral. Instead we found the opposite. This may indicate that Fral is not involved in the observed down regulation of GCLC and NQO1. We found increased AhRR gene expression with smoking. Cigarette smoke contains carcinogens such as polycyclic aromatic hydrocarbons that are metabolised by cytochrome P450 enzymes. Therefore AhRR is co-induced with cytochrome $\mathrm{P} 450$ enzymes via $\mathrm{XRE}^{(35)}$. Whether increased $A h R R$ expression in leucocytes is a marker for smoking needs further investigation. None of the other genes were transcribed differently as a function of smoking and there were no significant interactions between smoking and $\mathrm{pSe}$ on gene transcription.

Gene expression of phase 2 enzymes has been shown to vary with the studied organ, and results on whether blood expression profiles can be used as surrogate markers of organ expression are conflicting ${ }^{(36,37)}$. Finnstrom et al. found no correlation between blood and liver mRNA expression patterns of cytochrome P450 genes, but they noted that genes that were highly expressed in the liver at the same time could be expressed at lowered levels in the blood ${ }^{(38)}$. Rauchy et al. on the other hand found good correlation ${ }^{(39)}$. Results are inconclusive and further studies as to whether a blood sample can be used to determine the expression profile in target organs are needed. Furthermore, leucocytes are a mixture of many different cell types, and it has been shown that the profile of these cells vary from subject to subject based on cell type counts ${ }^{(37)}$. There might therefore be different expression profiles among different leucocyte cell types. Decreased gene expression of phase 2 enzymes in the blood compartment reported here may thus reflect changed composition of the leucocyte cell pool. It may also reflect altered expression in other tissues. In a study in transgenic mice containing a GCLC-luc construct, luciferase activity increased in brain and muscle but decreased in liver following treatments with berry extracts or ellagic acid ${ }^{(36)}$, indicating that complex up and down regulation may take place in different tissues as a response to redox active dietary components. We speculate that Se compounds may elicit similar complex actions in different tissues leading to an overall down regulation of EpRE-regulated genes in blood leucocytes.

We conclude that Se supplementation affects tGPX activity differently in men and women. Se status in healthy elderly Danish women is insufficient to obtain saturation of tGPX activity and higher Se intake might increase oxidative defence in this blood compartment. The present results indicate that $\mathrm{Se}$ supplementation can down regulate leucocyte genes having EpRE in their promoter and that Fral does not seem to be involved in down regulation of GCLC and NQO1 with Se. Decreased expression of EpRE-regulated genes could potentially increase the risk of cancer. However, further studies are needed to establish whether this down regulation in leucocytes reflects a similar expression pattern in other tissues.

\section{Acknowledgements}

We thank all those who volunteered for the study, Vibeke Kegel, Marianne Hansen, Geert Eisensee and her staff for excellent technical support, and Asta Christiansen and Hanne Hansen for their dedicated handling of the participants in the study. The present study was financially supported by a grant from the Danish Ministry of the Interior and Health, Research Centre for Environmental Health Fund.

The authors' responsibilities were as follows: S. C., K. O. and S. M. designed the original trial; L. O. D. designed the present sub-study; L. O. D. and E. H. L. obtained funding; S. C. supervised blood sample collection; B. N. K. was responsible for gene expression analyses; E. H. L. was responsible for Se analyses; G. R. H. was responsible for enzyme assays, undertook the statistical analyses and wrote the first draft of the manuscript; K. O. and L. O. D. provided statistical support. All authors approved the final manuscript. All authors declared that they had no conflict of interest.

\section{References}

1. Clark LC, Combs GF Jr, Turnbull BW, et al. (1996) Effects of selenium supplementation for cancer prevention in patients with carcinoma of the skin. A randomized controlled trial. Nutritional Prevention of Cancer Study Group. JAMA 276, 1957-1963. 
2. Clark LC, Dalkin B, Krongrad A, et al. (1998) Decreased incidence of prostate cancer with selenium supplementation: results of a double-blind cancer prevention trial. Br J Urol 81, 730-734.

3. Duffield-Lillico AJ, Slate EH, Reid ME, et al. (2003) Selenium supplementation and secondary prevention of nonmelanoma skin cancer in a randomized trial. J Natl Cancer Inst 95, $1477-1481$

4. Duffield-Lillico AJ, Reid ME, Turnbull BW, Combs GF Jr, Slate EH, Fischbach LA, Marshall JR \& Clark LC (2002) Baseline characteristics and the effect of selenium supplementation on cancer incidence in a randomized clinical trial: a summary report of the Nutritional Prevention of Cancer Trial. Cancer Epidemiol Biomarkers Prev 11, 630-639.

5. Combs GF Jr \& Gray WP (1998) Chemopreventive agents: selenium. Pharmacol Ther 79, 179-192.

6. Whanger PD (2004) Selenium and its relationship to cancer: an update. Br J Nutr 91, 11-28.

7. El-Bayoumy K \& Sinha R (2005) Molecular chemoprevention by selenium: a genomic approach. Mutat Res 591, 224-236.

8. Rao L, Puschner B \& Prolla TA (2001) Gene expression profiling of low selenium status in the mouse intestine: transcriptional activation of genes linked to DNA damage, cell cycle control and oxidative stress. J Nutr 131, 3175-3181.

9. El-Bayoumy K, Richie JP Jr, Boyiri T, Komninou D, Prokopczyk B, Trushin N, Kleinman W, Cox J, Pittman B \& Colosimo S (2002) Influence of selenium-enriched yeast supplementation on biomarkers of oxidative damage and hormone status in healthy adult males: a clinical pilot study. Cancer Epidemiol Biomarkers Prev 11, 1459-1465.

10. Gipp JJ, Chang C \& Mulcahy RT (1992) Cloning and nucleotide sequence of a full-length cDNA for human liver $\gamma$-glutamylcysteine synthetase. Biochem Biophys Res Commun 185, 29-35.

11. Gipp JJ, Bailey HH \& Mulcahy RT (1995) Cloning and sequencing of the cDNA for the light subunit of human liver $\gamma$-glutamylcysteine synthetase and relative mRNA levels for heavy and light subunits in human normal tissues. Biochem Biophys Res Commun 206, 584-589.

12. Chen C \& Kong AN (2004) Dietary chemopreventive compounds and ARE/EpRE signaling. Free Radic Biol Med 36, $1505-1516$

13. Yoshioka K, Deng T, Cavigelli M \& Karin M (1995) Antitumor promotion by phenolic antioxidants: inhibition of AP-1 activity through induction of Fra expression. Proc Natl Acad Sci U S A 92, 4972-4976.

14. Venugopal R \& Jaiswal AK (1996) Nrf1 and Nrf2 positively and c-Fos and Fra1 negatively regulate the human antioxidant response element-mediated expression of $\mathrm{NAD}(\mathrm{P}) \mathrm{H}$ :quinone oxidoreductase1 gene. Proc Natl Acad Sci U S A 93, 14960-14965.

15. Jardine H, MacNee W, Donaldson K \& Rahman I (2002) Molecular mechanism of transforming growth factor (TGF)$\beta 1$-induced glutathione depletion in alveolar epithelial cells. Involvement of AP-1/ARE and Fra-1. J Biol Chem 277, 21158-21166.

16. Li Y \& Jaiswal AK (1992) Regulation of human NAD(P)H:quinone oxidoreductase gene. Role of AP1 binding site contained within human antioxidant response element. J Biol Chem 267 , 15097-15104.

17. Mulcahy RT \& Gipp JJ (1995) Identification of a putative antioxidant response element in the $5^{\prime}$-flanking region of the human $\gamma$-glutamylcysteine synthetase heavy subunit gene. Biochem Biophys Res Commun 209, 227-233.

18. Reiter R \& Wendel A (1984) Selenium and drug metabolism II. Independence of glutathione peroxidase and reversibility of hepatic enzyme modulations in deficient mice. Biochem Pharmacol 33, 1923-1928.
19. Mimura J, Ema M, Sogawa K \& Fujii-Kuriyama Y (1999) Identification of a novel mechanism of regulation of $\mathrm{Ah}$ (dioxin) receptor function. Genes Dev 13, 20-25.

20. Cauchi S, Stucker I, Cenee S, Kremers P, Beaune P \& MassaadMassade L (2003) Structure and polymorphisms of human aryl hydrocarbon receptor repressor (AhRR) gene in a French population: relationship with CYP1A1 inducibility and lung cancer. Pharmacogenetics 13, 339-347.

21. Rayman MP (2000) The importance of selenium to human health. Lancet 356, 233-241.

22. Lyhne N, Christensen T, Groth MV, Fagt S, Biltoft-Jensen A, Hartkopp H, Hinsch H-J, Matthiessen J, Møller A, Saxholt E \& Trolle E (2005) Danskernes Kostvaner 2000-2002. Hovedresultater (Dietary Habits in Denmark 2000-2002. Main Results). Søborg, Denmark: Danish Institute for Food and Veterinary Research.

23. Larsen EH, Hansen M, Paulin H, Moesgaard S, Reid M \& Rayman M (2004) Speciation and bioavailability of selenium in yeast-based intervention agents used in cancer chemoprevention studies. J AOAC Int 87, 225-232.

24. Sloth JJ, Larsen EH, Bugel SH \& Moesgaard S (2003) Determination of total selenium and $\mathrm{Se} 77$ in isotopically enriched human samples by ICP-dynamic reaction cell-MS. JAAS 18, 317-322.

25. Wheeler CR, Salzman JA, Elsayed NM, Omaye ST \& Korte DW Jr (1990) Automated assays for superoxide dismutase, catalase, glutathione peroxidase, and glutathione reductase activity. Anal Biochem 184, 193-199.

26. Dragsted LO, Pedersen A, Hermetter A, Basu S, Hansen M, Haren GR, Kall M, Breinholt V, Castenmiller JJ, Stagsted J, Jacobsen J, Skibsted L, Rasmussen SE, Loft S \& Sandström B (2004) The 6-a-day study: effects of fruit and vegetables on markers of oxidative stress and antioxidative defense in healthy nonsmokers. Am J Clin Nutr 79, 1060-1072.

27. Alfthan G, Aro A, Arvilommi H \& Huttunen JK (1991) Selenium metabolism and platelet glutathione peroxidase activity in healthy Finnish men: effects of selenium yeast, selenite, and selenate. Am J Clin Nutr 53, 120-125.

28. Thomson CD, Robinson MF, Butler JA \& Whanger PD (1993) Long-term supplementation with selenate and selenomethionine: selenium and glutathione peroxidase $(E C$ 1.11.1.9) in blood components of New Zealand women. Br J Nutr 69, 577-588.

29. Levander OA, Alfthan G, Arvilommi H, Gref CG, Huttunen JK, Kataja M, Koivistoinen P \& Pikkarainen J (1983) Bioavailability of selenium to Finnish men as assessed by platelet glutathione peroxidase activity and other blood parameters. Am J Clin Nutr 37, 887-897.

30. Nève J (1995) Human selenium supplementation as assessed by changes in blood selenium concentration and glutathione peroxidase activity. J Trace Elem Med Biol 9, 65-73.

31. Nève J, Vertongen F \& Capel P (1988) Selenium supplementation in healthy Belgian adults: response in platelet glutathione peroxidase activity and other blood indices. Am J Clin Nutr $\mathbf{4 8}$ 139-143.

32. Brown KM, Pickard K, Nicol F, Beckett GJ, Duthie GG \& Arthur JR (2000) Effects of organic and inorganic selenium supplementation on selenoenzyme activity in blood lymphoctyes, granulocytes, platelets and erythrocytes. Clin Sci (Lond) 98, 593-599.

33. Bukkens SG, de Vos N, Kok FJ, Schouten EG, de Bruijn AM \& Hofman A (1990) Selenium status and cardiovascular risk factors in healthy Dutch subjects. J Am Coll Nutr 9, $128-135$.

34. Ravn-Haren G, Olsen A, Tjonneland A, Dragsted LO, Nexo BA, Wallin H, Overvad K, Raaschou-Nielsen O \& Vogel U (2006) Associations between GPX1 Pro198Leu polymorphism, 
erythrocyte GPX activity, alcohol consumption and breast cancer risk in a prospective cohort study. Carcinogenesis 27, $820-825$.

35. Tsuchiya Y, Nakajima M, Itoh S, Iwanari M \& Yokoi T (2003) Expression of aryl hydrocarbon receptor repressor in normal human tissues and inducibility by polycyclic aromatic hydrocarbons in human tumor-derived cell lines. Toxicol Sci 72, 253-259.

36. Carlsen H, Myhrstad MC, Thoresen M, Moskaug JO \& Blomhoff R (2003) Berry intake increases the activity of the $\gamma$-glutamylcysteine synthetase promoter in transgenic reporter mice. J Nutr 133, 2137-2140.
37. Whitney AR, Diehn M, Popper SJ, Alizadeh AA, Boldrick JC, Relman DA \& Brown PO (2003) Individuality and variation in gene expression patterns in human blood. Proc Natl Acad Sci U S A 100, 1896-1901.

38. Finnstrom N, Thorn M, Loof L \& Rane A (2001) Independent patterns of cytochrome $\mathrm{P} 450$ gene expression in liver and blood in patients with suspected liver disease. Eur J Clin Pharmacol 57, 403-409.

39. Raucy JL, Schultz ED, Wester MR, Arora S, Johnston DE, Omdahl JL \& Carpenter SP (1997) Human lymphocyte cytochrome P450 2E1, a putative marker for alcohol-mediated changes in hepatic chlorzoxazone activity. Drug Metab Dispos 25, 1429-1435. 